\title{
Mesial temporal haemorrhage, consequence of status epilepticus
}

\author{
P. N O $\ddot{E} L, A$. C O R N I L, P. C H A I L L Y, A N D \\ J. F L A M E N T - D U R A N D \\ From the Departments of Medicine and Pathology, Université Libre de Bruxelles, Brussels, Belgium
}

SUMMARY A 52 year old woman developed a severe encephalopathy with status epilepticus of six days duration in the terminal course of an acute hepatitis associated with hyperammonaemia and hyperventilation. Acute haemorrhagic lesions were observed in the brain, involving symmetrically both amygdala and cornu Ammonis. The sequential occurrence of these lesions with status epilepticus are discussed in the light of data from the literature.

Numerous reports have delineated the pathological findings in status epilepticus (Fowler, 1957; Scholz, 1959; Norman, 1964): ischaemic lesions and glial reactions are observed in selectively vulnerable regions. These lesions are commonly held to be the consequence and not the cause of the convulsive status (Meldrum, 1976). However, in a number of cases, this relation cannot be ascertained, particularly when the pathological findings reveal old gliotic hippocampal lesions. They could precede and be responsible for the initiation of convulsions.

In the case reported here, the unusual character of the lesions leaves no doubt about the sequence of events: they are acute and secondary to the status epilepticus.

\section{Case report}

A 52 year old woman was admitted for treatment of coma and convulsive seizures. One month earlier she had been admitted to another hospital for pyrexia and exertion dyspnoea. The physical examination was normal except for a slight pyrexia. Liver biopsy showed no pathological alterations. She was discharged without further investigations.

Address for reprint requests: Dr J. Flament-Durand, Department of Pathology, Faculty of Medicine, rue aux Laines 97, B-1000 Brussels, Belgium.

Accepted 21 March 1977
The day before the final admission, she complained of headache and vomited repeatedly. A few hours later, she was found obtunded with recurrent generalised convulsions. The medical history was unremarkable. She had never presented epileptic fits nor indulged in alcoholism.

On admission, the rectal temperature was $38.2^{\circ} \mathrm{C}$, the pulse rate $100 / \mathrm{min}$, the blood pressure $120 / 70 \mathrm{mmHg}$, and the respiratory rate $40 / \mathrm{min}$. She was unconscious and reacted to painful stimuli by semi-purposeful movements. No jaundice or rash were present. Coarse rales were audible throughout both lungs. The heart and abdomen were normal. There was prominent acrocyanosis with peripheral vasoconstriction and unpalpable arteries. Eye movements were full, with spontaneous roving movements. The right pupil was $2 \mathrm{~mm}$ wide, the left pupil $4 \mathrm{~mm}$; they both reacted to light. The ocular fundi and the cranial nerves were normal. The deep reflexes were present with a flexor plantar reaction. Treatment consisted of tracheal intubation, assisted ventilation, rehydration, phenobarbitone, phenytoin, dexamethasone, and ampicillin. The urine was normal. The haematocrit was $29.7 \%$, the white cell count was 11300 per $\mathrm{mm}^{3}$ with $90 \%$ neutrophils, $6 \%$ lymphocytes, $2 \%$ monocytes and $2 \%$ metamyelocytes. The platelet count was 340000 per $\mathrm{mm}^{3}$. The urea nitrogen was $0.72 \mathrm{~g} / 1$, the glucose $1.82 \mathrm{~g} / 1$, the bilirubin 0.031 $\mathrm{g} / 1$ and the protein $7.1 \mathrm{~g} / 1$ (albumin $40.5 \%$, alpha1 globulins $5.5 \%$, alpha-2 globulins $8 \%$, beta globulins $6.4 \%$, and gamma globulins $38.6 \%$ ). The 
glutamic oxalacetic transaminase (SGOT) level was $1650 \mathrm{IU} / 1$, the glutamic pyruvic transaminase $620 \mathrm{IU} / 1$. The serum sodium level was $138 \mathrm{mmol}$, potassium $3.9 \mathrm{mmol}$, chloride $95 \mathrm{mmol}$, and calcium $4.3 \mathrm{mmol} / 1$. There were no LE cells. The prothrombin time was $21 \%$ of normal. A spinal tap was performed. The opening pressure was 12 $\mathrm{mmH}_{2} \mathrm{O}$; the fluid was clear. The CSF protein content was $0.42 \mathrm{~g} / \mathrm{l}$ and there were no cells.

On the second day, she presented numerous generalised seizures which were refractory to treatment by intravenous diazepam and clonazepam.

On the third day the patient reacted to painful stimuli by decerebrate posturing. The pupils were equal and reacted sluggishly to light. The deep reflexes were hyperactive in the four limbs with a bilateral Babinski sign.

On the fourth day, seizures were permanent, interrupted only by short periods of total hypotonia. Mucosal and cutaneous jaundice was prominent. The serum bilirubin was $0.10 \mathrm{~g} / 1$. A spinal tap revealed clear CSF with $3.20 \mathrm{~g} / 1$ protein, and 154 red cells $/ \mathrm{ml}$. A brain Te scan and carotid angiography disclosed no abnormal feature.

On the fifth day, the patient did not react to stimuli. The pupil reflexes were still present. The seizures were lateralised either to the right or to the left limbs. The EEG disclosed diffuse polymorphic slow waves (Fig. 1). A generalised seizure was recorded, initiated by spike activity on the right side. The temperature rose to $41^{\circ} \mathrm{C}$. The patient died on her sixth day in hospital.

\section{PATHOLOGY}

Visceral necropsy showed congestion and oedema of both lungs and foci of bronchopneumonia, confirmed by histological examination which, in addition, showed the presence of filamentous fungi in the inflammatory lesions. The liver was small, weighing $975 \mathrm{~g}$, soft and yellow, presenting a smooth surface. Histological examination revealed large areas of necrosis, steatosis of some hepatocytes, phagocytosis of lipofuscin granules by Kupffer cells, slight fibrosis of the portal vessels, and biliary stasis. Histolytic changes were prominent, possibly due to the hyperthermia presented by the patient a few days before death. The heart, spleen, and kidneys were unremarkable.

On macroscopic examination, the brain appeared normal. The arteries forming the circle of Willis were of normal aspect and anatomical configuration. There was no temporal herniation and the mammillary bodies were of normal size. On coronal section, symmetrical lesions with a striking haemorrhagic character were seen, involving the anterior white commissure, the amygdala, and the cornu Ammonis (Fig. 2). Histological examination of these areas confirmed haemorrhagic necrosis of recent character, without any microglial or astrocytic reactions. In one of the Ammon's horns, in addition to these haemorrhagic lesions, a small solitary mycotic abscess was observed. The inflammatory infiltration consisted of polynuclear cells and the same filamentous fungi as those seen in the lungs were observed. This lesion was minute and well demarcated. Scattered ischaemic lesions were seen in the Purkinje cells and the temporal neurones. The hypothalamus, brainstem, and basal ganglia were intact.

\section{Discussion}

This patient presented a severe encephalopathy with status epilepticus of six days duration. It was associated with an acute, probably viral, hepatitis assessed by evidence of liver necrosis, hyperam-

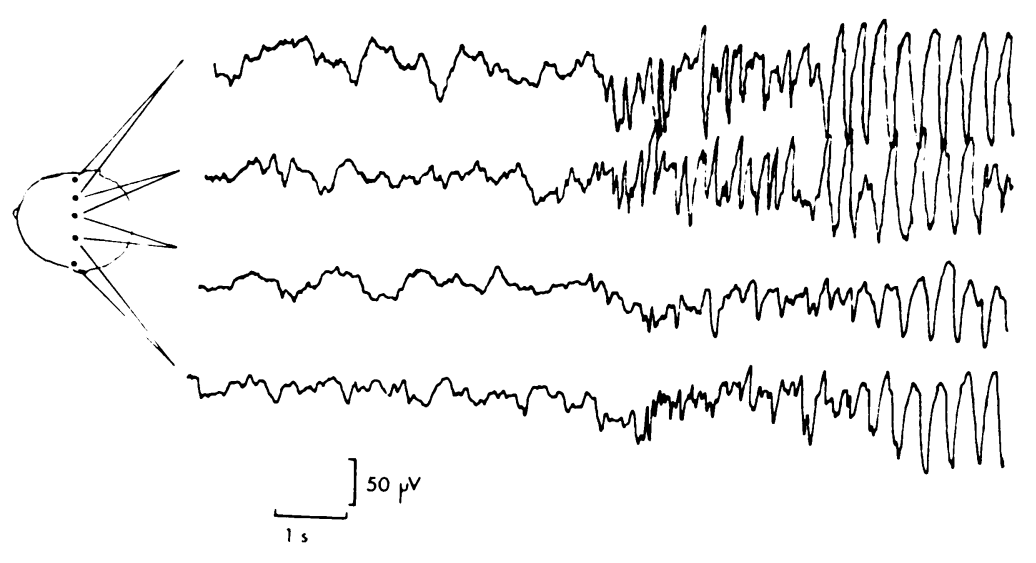

Fig. 1 EEG recording of a generalised seizure with initial right sided polyspikes. Transverse leads. 


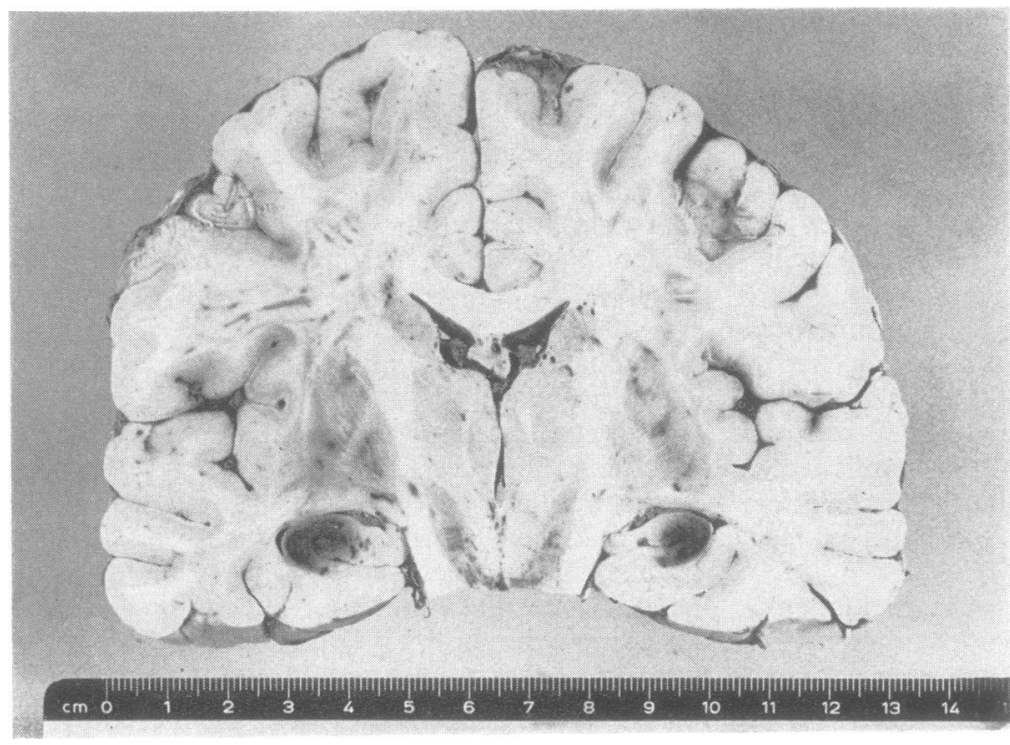

Fig. 2 Coronal section of the brain showing symmetrical haemorrhagic lesions of the cornu Ammonis. monaemia, and hyperventilation. The usual signs of hepatic coma were absent, notably the asterixis and extrapyramidal syndrome, but convulsions were prominent which are rarely seen in the absence of an associated alcohol withdrawal syndrome (Adams and Foley, 1953). Encephalomyelitis was described in the early stage of viral hepatitis (Thorling, 1950; Friedlander, 1956). It was characterised by altered state of consciousness and various neurological deficits but convulsions were only reported in children. By contrast, severe seizures are common with acute encephalopathy associated with the fatty liver degeneration described in children (Reye et al., 1963) and attributed to unspecified virus or toxins. In this latter syndrome, death would result from the increased intracranial pressure and uncal herniation, rather than from the hepatic insufficiency (Kindt et al., 1975).

However, the necropsy findings in our case are not consistent with this diagnosis. The liver showed discrete steatosis and large areas of necrosis with incipient portal fibrosis confirming an acute hepatitis. Death resulted from intractable convulsive status, but no evidence of uncal herniation was apparent. Haemorrhagic infarction was found in the Ammon's horn and amygdala. The distribution is comparable to the 'mesial temporal sclerosis' observed in $50-70 \%$ of patients with longstanding epilepsy (Sano and Malamud, 1953; Falconer et al., 1964; Falconer, 1974) though the exact relationship between both findings has been much debated.
Experimental evidence has been presented that mesial temporal sclerosis may be produced by prolonged seizures. Meldrum et al. $(1973 \mathrm{a}, \mathrm{b})$ provided a primate model of hippocampal sclerosis induced by epileptic activity. Sustained generalised seizures triggered by intravenous bicuculline were shown to induce ischaemic changes in the Ammon's horns, the amygdala, thalamus, Purkinje cells, and the 3rd and 4th layers of the cortex. The incidence of these ischaemic cell changes was related to the total duration of seizure activity. The distribution of the damage, with the emphasis on the hippocampus and the almost invariable sparing of the calcarine cortex (Ounsted et al., 1966) is different from that which usually results from an obstruction of the posterior cerebral artery, which rules out an uncal herniation secondary to an increased supratentorial pressure. It may be postulated that the hippocampal lesions result from coincidence of systemic hypoxia, hypoglycaemia, arterial hypotension and hyperthermia, and local vascular factors (Brierley et al., 1971).

Of significance could be the close relation between the hippocampus and the free edge of the cerebellar tentorium. Indeed the Ammon's horn is irrigated by a long collateral branch of the posterior cerebral artery quoted by Lindenberg (1955) as the Uchimura artery, after its first description (1928). In cerebral oedema accompanying status epilepticus, this artery could be squeezed between the brainstem and the free edge of the tentorium, thus producing selective ischaemic 
changes in the Sommer's sector and the terminal plate of the hippocampus. Simultaneous involvement of the Ammon's horn and the amygdala has already been reported by Meyer et al. (1955) in status epilepticus and could imply additional interference with the blood supply in the territory of the anterior choroidal arteries.

The scarring of the hippocampal lesions could eventually lead to secondary temporal seizures, accounting for the gliotic sclerosis commonly seen in the temporal lobes of patients with longstanding epilepsy.

In our patient, status epilepticus lasted for six days which is sufficient to induce cerebral damage (Scholz, 1959). The liver insufficiency and defective coagulation mechanisms probably account for the unusual haemorrhagic character of the lesions. In any case, this peculiarity clearly underlines an acute lesion of recent onset, thus secondary and not primary to the convulsive status. By comparison with the accepted denomination of mesial temporal sclerosis, this lesion complex could be called mesial temporal haemorrhage.

The cause of the status epilepticus remains unclear. In the encephalitis complicating hepatitis previously quoted (Friedlander, 1956) the only pathological finding was cerebral venous congestion without inflammatory infiltration. It cannot be ruled out that the fungal abscess found in one Ammon's horn could have been a critical factor in initiating the convulsive seizures, though such parasitic complications are by no means rare in fatal hepatic disease and usually go unnoticed until necropsy.

\section{References}

Adams, R. D., and Foley, J. M. (1953). The neurological disorder associated with liver disease. Research Publications, Association for Research in Nervous and Mental Diseases, 32, 198-237.

Brierley, J. B., Brown, A. W., and Meldrum, B. S. (1971). The nature and time course of the neuronal alterations resulting from oligaemia and hypoglycaemia in the brain of Macaca mulata. Brain Research, 25, 483-499.

Falconer, M. A. (1974). Mesial temporal (Ammon's horn) sclerosis as a common cause of epilepsy. Aetiology, treatment and prevention. Lancet, 2 , 767-770.

Falconer, M. A.. Serafetinides, E. A., and Corsellis, J. A. N. (1964). Etiology and pathogenesis of tem- poral lobe epilepsy. Archives of Neurology (Chicago), 10, 233-248.

Fowler, M. (1957). Brain damage after febrile convulsions. Archives of Disease in Childhood, 32, 6776.

Friedlander, W. J. (1956). Neurological signs and symptoms as a prodrome to virus hepatitis. Neurology (Minneapolis), 6, 574-579.

Kindt, G., Waldman, J., Kohl, S., Baublis, J., and Tucker, R. T. (1975). Intracranial pressure in Reye syndrome. Journal of the American Medical Association. 231, 822-825.

Lindenberg, R. (1955). Compression of brain arteries as pathogenetic factor for tissue necrosis and their area of predilection. Journal of Neuropathology and Experimental Neurology, 14, 223-243.

Meldrum, B. S. (1976). Neuropathology and pathophysiolcgy. In $A$ Textbook of Epilepsy. Fdited by J. Laidlaw and A. Richens, pp. 314-354. Churchill Livingstone: Edinburgh, London, New York.

Meldrum, B. S.. and Horton, R. W. (1973a). Physiology of status epilepticus in primates. Archives of Neurology (Chicago), 28, 1-10.

Meldrum, B. S., and Brierley, J. B. (1973b). Prolonged epileptic seizures in primates. Archives of Neurology (Chicago), 28, 10-17.

Meyer. A., Beck, E., and Shepherd, M. (1955). Lesions in brain following status epilepticus. Journal of Neurology, Neurosurgery, and Psychiatry, 18, 24-33.

Norman, R. M. (1964). The neuropathology of status epilepticus. Medical Science Law, 4, 46-51.

Ounsted, C., Lindsay, J.. and Norman, R. (1966). Biological factors in temporal lobe epilepsy. Clinics in Developmental Medicine, Vol. 22. William Heinemann Medical Books: London.

Reye, R. D. K., Morgan, G., and Baral. J. (1963). Encephalopathy and fatty degeneration of the viscera: a disease entity in childhood. Lancet, 2, 749-752.

Sano, K., and Malamud, N. (1953). Clinical significance of sclerosis of the cornu Ammonis. Archives of Neurology and Psychiatry (Chicago), 70, 4053.

Scholz, W. (1959). The contribution of pathoanatomical research to the problem of epilepsy. Epilepsia, 1, 36-55.

Thorling, L. (1950). Neurological complications in acute infectious hepatitis. Acta Medica Scandinavica. 137, 322-334.

Uchimura, J. (1928). Über die Gafäszversorgung des Ammonshornes. Zeitschrift für die Gesamte Neurologie und Psychiatrie, 112, 1-19.

Uchimura, J. (1928). Zur Pathogenesis der örtlich elektiven Ammonshorn Erkrankung. Zeitschrift für die Gesamte Neurologie und Psychiatrie, 114, $567-601$. 